\begin{tabular}{|c|c|c|c|c|c|c|}
\hline \multirow{4}{*}{ Impact Factor: } & ISRA (India) & $=3.117$ & SIS (USA) & $=0.912$ & ICV (Poland) & $=6.630$ \\
\hline & ISI (Dubai, UAE & $=0.829$ & РИНЦ (Russia & $=\mathbf{0 . 1 5 6}$ & PIF (India) & $=1.940$ \\
\hline & GIF (Australia) & $=0.564$ & ESJI (KZ) & $=8.716$ & IBI (India) & $=4.260$ \\
\hline & JIF & $=1.500$ & SJIF (Morocco & $=\mathbf{5 . 6 6 7}$ & OAJI (USA) & $=0.350$ \\
\hline
\end{tabular}

\begin{tabular}{|c|c|}
\hline $\begin{array}{l}\text { SOI: } 1.1 / \mathrm{T} \\
\text { International S } \\
\text { Theoretical } \mathbf{\&}\end{array}$ & $\begin{array}{l}\text { AS } \text { DOI: } 10.15863 / \mathrm{TAS} \\
\text { cientific Journal } \\
\text { Applied Science }\end{array}$ \\
\hline p-ISSN: 2308-4944 (print) & e-ISSN: 2409-0085 (online) \\
\hline Year: 2019 Issue: 04 & Volume: 72 \\
\hline Published: 11.04 .2019 & http://T-Science.org \\
\hline
\end{tabular}

SECTION 9. Chemistry and chemical technology.
QR - Issue

QR - Article
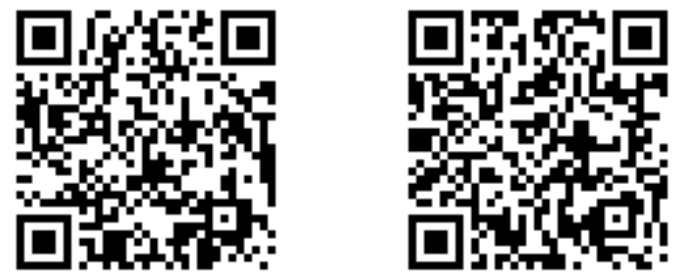

Igor Viktorovich Goloperov Candidate of chemical sciences, Docent, Department of Occupational Health and Environmental Safety, Ukrainian Engineering and Pedagogical Academy,

Ukraine

goloperov_igor_2018@ukr.net

Aleksandr Nikolaevich Baklanov

Doctor of chemical sciences, Professor,

Head of the Department of Occupational Health and

Environmental Safety,

Ukrainian Engineering and

Pedagogical Academy, Ukraine

baklanov_oleksandr@meta.ua

Larisa Vladimirovna Baklanova

Candidate of chemical sciences, Docent,

Head of the Department of Occupational Health and

Environmental Safety,

Ukrainian Engineering and

Pedagogical Academy, Ukraine

baklanovalarisa@ukr.net

\title{
SOLUTION TO THE PROBLEM OF SAFETY OF COOKED SALT. ULTRASOUND IN THE CLEANING OF COOKED SALT FROM IMPURITIES OF ARSENIC, CADMIUM AND COPPER
}

\footnotetext{
Abstract: The proposed solution to the problem of safety of salt - a new approach to the purification of concentrated solutions of salt $(\geq 280 \mathrm{~g} / \mathrm{l})$ from impurities of toxic elements: arsenic, cadmium and copper. It was established experimentally that when cleaning concentrated solutions of sodium chloride $\geq 280 \mathrm{~g} / \mathrm{l}$, using as a collector a mixture of magnesium hydroxide and calcium carbonate, with an amount of magnesium hydroxide not less than $4 \mathrm{mmol} / \mathrm{l}$, and calcium hydroxide $1-2 \mathrm{mmol} / \mathrm{l}$ with the intensification effect ultrasound with a frequency of $18-53 \mathrm{kHz}$, an intensity of $1.0-2.5 \mathrm{~W} / \mathrm{cm}^{2}$ and ultrasound with a frequency of $2-4 \mathrm{MHz}$ with an intensity of $0.75-$ $1.25 \mathrm{~W} / \mathrm{cm}^{2}$ for $30-45 \mathrm{~s}$ allows an increase in the degree of purification of concentrated solutions of sodium chloride from $12-33 \%$ to $90-97 \%$.

Key words: safety, salt, ultrasound, frequency, intensity, arsenic, copper, cadmium.

Language: Russian

Citation: Goloperov, I. V., Baklanov, A. N., \& Baklanova, L. V. (2019). Solution to the problem of safety of cooked salt. Ultrasound in the cleaning of cooked salt from impurities of arsenic, cadmium and copper. ISJ Theoretical \& Applied Science, 04 (72), 85-91.

Soi: http://s-o-i.org/1.1/TAS-04-72-16 Doi: crossef https://dx.doi.org/10.15863/TAS.2019.04.72.16

\section{РЕШЕНИЕ ПРОБЛЕМ БЕЗОПАСНОСТИ ПОВАРЕННОЙ СОЛИ. УЛЬТРАЗВУК В ОЧИСТКЕ ПОВАРЕННОЙ СОЛИ ОТ ПРИМЕСЕЙ МЫШЬЯКА, КАДМИЯ И МЕДИ}

Аннотация: Предложено решение проблемы безопасности поваренной соли - новый подход к очистке концентрированных растворов поваренной соли ( $\geq 280$ г/л) от примесей токсичных элементов: мышьяка,
} 


\begin{tabular}{|c|c|c|c|c|c|c|}
\hline \multirow{4}{*}{ Impact Factor: } & ISRA (India) & $=3.117$ & SIS (USA) & $=0.912$ & ICV (Poland) & $=6.630$ \\
\hline & ISI (Dubai, UAE & $=0.829$ & РИНЦ (Russia & $=0.156$ & PIF (India) & $=1.940$ \\
\hline & GIF (Australia) & $=0.564$ & ESJI (KZ) & $=8.716$ & IBI (India) & $=4.260$ \\
\hline & JIF & $=1.500$ & SJIF (Morocco & $=\mathbf{5 . 6 6 7}$ & OAJI (USA) & $=0.350$ \\
\hline
\end{tabular}

кадмия и меди. Экспериментально установлено, что при очистке концентрированных растворов поваренной соли $\geq 280$ г/л, использование в качестве коллектора смеси гидроксида магния и карбоната кальиия, при количестве гидроксида магния не менее 4 ммоль/л, а гидроксида кальиия 1 - 2 ммоль/л с интенсификацией воздействием ультразвука частотой $18-53 \kappa Г$ и, интенсивностью $1,0-2,5 \mathrm{Bm} / \mathrm{cm}^{2}$ и ультразвука частотой

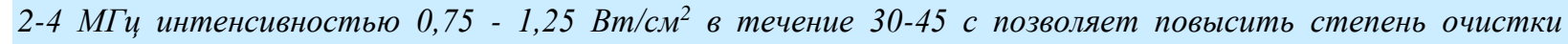
кониентрированных растворов поваренной соли с $12-33 \%$ до 90-97\%.

Ключевые слова: безопасность, поваренная соль, ультразвук, частота, интенсивность, мыцияк, медь, кадмий.

\section{Введение.}

Поваренная соль является важнейшим пищевым продуктом. Безопасность поваренной соли определяется содержанием примесей токсичных элементов. Причем, очистка от примесей мышьяка, кадмия и меди считается сложной технологической задачей $[1,2]$.

Описан [3] способ очистки поваренной соли, включающий складывание ее в бурты и промывку атмосферными осадками от солей магния и нерастворимых в воде примесей [1]. Недостатком способа является длительность процесса, занимает 3-4 месяца, потери готовой продукции $15-20 \%$ и недостаточная степень очистки от примесей токсичных элементов мышьяка, меди и кадмия, не превышающая 5\% [3].

Также описан способ очистки поваренной соли, включающий ее охлаждение до температуры $(-15)$ - $(-20)^{\circ} \mathrm{C}$, растворение в пероксиде водорода под действием ультразвука (УЗ) частотой $18-100$ кГц, интенсивностью $0,15 \ldots 0,25 \mathrm{~B} / \mathrm{cm}^{2}$ и УЗ частотой 1,0 - 2,5 МГц, интенсивностью $0,25 \ldots$ $0,50 \mathrm{BT} / \mathrm{cm}^{2}$ (при этих условиях растворяется только хлорид натрия), фильтрование раствора и кристаллизацию хлорида натрия при температуре 130 - $150{ }^{\circ} \mathrm{C}$ [ 4]. Недостатком способа является сложность процесса, связанная с необходимостью охлаждения поваренной соли до температуры (15) - $(-20)^{\circ} \mathrm{C}[4]$.

Наиболее эффективным является способ очистки поваренной соли, включающий растворение поваренной соли в воде и соосаждение примесей на коллекторе - гидроксиде магния при рН 12-13 при воздействии УЗ частотой 22 - 44 кГц, интенсивностью $1,7-3,5$ Вт/см ${ }^{2}$ в течение 20-25 с. Способ позволяет очищать растворы поваренной соли концентрацией до 140 г/л от примесей мышьяка, меди и кадмия со степенью очистки 98 - 99\%. Недостатком способа является недостаточная степень очистки концентрированных растворов поваренной соли $\geq$ 280 г / л, что не превышает для мышьяка - 12\%, для меди - 33\%, для кадмия - 29\%. В связи с чем, эффективность процесса очистки значительно уменьшается [5].

Известно, что для интенсификации массообменных процессов наиболее эффективным является использование одновременного воздействия УЗ высокой и низкой частот [6].
Предлагаемая работа посвящена изучению использования двухчастотного УЗ в интенсификации процессов очистки растворов поваренной соли $\geq 280$ г/л от примесей мышьяка, кадмия и меди.

\section{Экспериментальная часть}

При выполнении данной работы применяли ультразвуковой диспергатор УЗДН - $1 \mathrm{M}$ с набором магнитострикционных излучателей, что позволяло создавать в исследуемой системе ультразвуковые колебания частотой от 16 кГц до 100 кГц при интенсивности УЗ до 25 Вт/см² $[7,8]$. Также использовали УЗ генератор типа 24-УЗГИК-1,2 с набором пьезоэлектрических излучателей типа ЦТС-19, что позволяло создавать в изучаемых растворах ультразвуковые колебания частотой 0,9 - 3,5 МГц с интенсивностью до 12 $\mathrm{BT} / \mathrm{cm}^{2}$ (ограничивалась прочностью излучателя) [9].

Опыты проводили следующим образом. В химические стаканы вместимостью 1500 мл вводили по 1000 мл раствора поваренной соли концентрацией 140, 180, 200, 250, 280, 300, 320 г/л. Приливали по 4 мл 1 М раствора хлорида магния и по 1 мл 1 М раствора хлорида кальция и $3 \mathrm{M}$ раствор гидроксида натрия до рН 12 (10 мл). На полученную смесь действовали УЗ частотой $0,9-$ 3,5 МГц интенсивностью $0,7-1,25$ Вт/см ${ }^{2}$ и ультразвуком частотой 22 кГц, интенсивностью $1,5 \mathrm{BT} / \mathrm{cm}^{2}$ в течение 30 с. Отделяли осадок от раствора сифонированием и центрифугированием. В полученном растворе определяли содержание меди и кадмия атомноабсорбционным методом [10], а мышьяка спектрофотометрическим методом с диэтилдитиокарбаматом серебра [11].

\section{Результаты и их обсуждение}

В табл. 1 приведены результаты опытов по изучению влияния частоты высокочастотного УЗ на степень очистки поваренной соли. Как следует из табл. 1 оптимальной частотой УЗ является 1,03,0 МГц. При использовании У3 менее 1,0 МГц, степень очистки поваренной соли уменьшается. При увеличении частоты УЗ более чем 3,0 МГц также уменьшается степень очистки поваренной соли. Вероятно, что диапазон частот высокочастотного УЗ 1,0-3,0 МГц является оптимальным для интенсификации данных процессов. 


\begin{tabular}{|c|c|c|c|c|c|c|}
\hline \multirow{4}{*}{ Impact Factor: } & ISRA (India) & $=3.117$ & SIS (USA) & $=0.912$ & ICV (Poland) & $=6.630$ \\
\hline & ISI (Dubai, UAE & $=0.829$ & РИНЦ (Russia) & $=0.156$ & PIF (India) & $=1.940$ \\
\hline & GIF (Australia) & $=0.564$ & ESJI (KZ) & $=8.716$ & IBI (India) & $=4.260$ \\
\hline & JIF & $=1.500$ & SJIF (Morocco) & $=5.667$ & OAJI (USA) & $=0.350$ \\
\hline
\end{tabular}

Таблица 1. Влияние частоты высокочастотного ультразвука на степень очистки поваренной соли

\begin{tabular}{|c|c|c|c|}
\hline \multirow{2}{*}{ Частота УЗ, МГц } & \multicolumn{3}{|c|}{ Степень очистки поваренной соли, \% } \\
\cline { 2 - 4 } & Мышьяк & Медь & Кадмий \\
\hline 0,9 & 74 & 85 & 97 \\
\hline 1,0 & 91 & 98 & 91 \\
\hline 2,0 & 92 & 97 & 91 \\
\hline 3,0 & 90 & 97 & 78 \\
\hline 3,1 & 88 & 89 & 92 \\
\hline
\end{tabular}

В этой таблице и последующих приведены усредненные результаты шести опытов, а для очистки использован раствор поваренной соли концентрачией 280 г/л.

Частота низкочастотного УЗ 22,0 кГц, интенсивность низкочастотного УЗ $1,5 \mathrm{BT} / \mathrm{cm}^{2}$. Интенсивность высокочастотного УЗ $0,75 \mathrm{BT} / \mathrm{cm}^{2}$, время воздействия УЗ 30 с. Концентрация гидроксида магния 4 ммоль/л, концентрация карбоната кальция - 1 ммоль/л.

В табл. 2 приведено влияние частоты низкочастотного УЗ на степень очистки поваренной соли. Как следует из табл. 2 оптимальной частотой УЗ является 18 - 53 кГц. При использовании УЗ частотой менее 18 кГц степень очистки поваренной соли уменьшается. При увеличении частоты УЗ более чем 53 кГц также уменьшается степень очистки поваренной соли.

Таблица 2. Влияние частоты низкочастотного ультразвука на степень очистки поваренной соли

\begin{tabular}{|c|c|c|c|}
\hline \multirow{2}{*}{ Частота УЗ, кГц } & \multicolumn{3}{|c|}{ Степень очистки поваренной соли, \% } \\
\cline { 2 - 4 } & Мышьяк & Медь & Кадмий \\
\hline 17 & 87 & 85 & 89 \\
\hline 18 & 93 & 97 & 91 \\
\hline 22 & 90 & 97 & 92 \\
\hline 53 & 90 & 96 & 83 \\
\hline 54 & 80 & 81 & 91 \\
\hline
\end{tabular}

Частота высокочастотного УЗ 3,0 МГи. Интенсивность низкочастотного УЗ 1,5 Вт/см ${ }^{2}$. Интенсивность высокочастотного УЗ $0,75 \mathrm{Bm} / \mathrm{cm}^{2}$, время воздействия УЗ $30 \mathrm{c}$. Концентрачия гидроксида магния 4 ммоль/л, кониентрация карбоната кальиия - 1 ммоль/л.

В табл. 3 приведено влияние интенсивности высокочастотного УЗ на степень очистки поваренной соли. Как следует из табл. 3 оптимальной интенсивностью высокочастотного ультразвукаУЗ является $0,75-1,20$ Вт/см². При использовании высокочастотного УЗ интенсивностью менее $0,75 \quad$ Вт/см ${ }^{2}$ степень очистки поваренной соли уменьшается. При увеличении интенсивности УЗ ультразвука более чем $1,20 \mathrm{BT} / \mathrm{cm}^{2}$ также уменьшается степень очистки поваренной соли. При использовании только одного низкочастотного УЗ степень очистки поваренной соли резко уменьшилась.

Таблица 3. Влияние интенсивности высокочастотного ультразвука на степень очистки поваренной соли

\begin{tabular}{|c|c|c|c|}
\hline \multirow{2}{*}{$\begin{array}{c}\text { Интенсивность У3, } \\
\text { Вт/см }\end{array}$} & \multicolumn{3}{|c|}{ Степень очистки поваренной соли, \% } \\
\cline { 2 - 4 } & Мышьяк & Медь & Кадмий \\
\hline 0,74 & 85 & 89 & 80 \\
\hline 0,75 & 90 & 97 & 91 \\
\hline 1,00 & 91 & 98 & 92 \\
\hline 1,20 & 92 & 96 & 85 \\
\hline 1,21 & 83 & 88 & 29 \\
\hline$*$ & 12 & 33 & 92 \\
\hline
\end{tabular}

Частота высокочастотного УЗ 3,0 МГи. Частота низкочастотного ультразвука 22,0 кГи. Ин-тенсивнисть низкочастотного ультразвука 1,5 Bm/cм². Время действия ультразвука 30 с. Концентрация гидроксида магния 4 ммоль/л, кониентрация карбоната кальция - 1 ммоль/л. * Без действия высокочастотной составляющей ультразвука (действует только низкочастотный ультразвук). 


\begin{tabular}{|c|c|c|c|c|c|c|}
\hline \multirow{4}{*}{ Impact Factor: } & ISRA (India) & $=3.117$ & SIS (USA) & $=0.912$ & ICV (Poland) & $=6.630$ \\
\hline & ISI (Dubai, UAE & $=0.829$ & РИНЦ (Russia & $=\mathbf{0 . 1 5 6}$ & PIF (India) & $=1.940$ \\
\hline & GIF (Australia) & $=0.564$ & ESJI (KZ) & $=8.716$ & IBI (India) & $=4.260$ \\
\hline & JIF & $=1.500$ & SJIF (Morocco & $=5.667$ & OAJI (USA) & $=0.350$ \\
\hline
\end{tabular}

В табл. 4 приведено влияние интенсивности низкочастотного УЗ на степень очистки поваренной соли. Как следует из табл. 4 оптимальной интенсивностью низкочастотного У3 является 1,0-2,0 Вт/ см². При использовании низкочастотного УЗ интенсивностью менее 1,0 $\mathrm{B} / \mathrm{cm}^{2}$ степень очистки поваренной соли уменьшается. При увеличении интенсивности

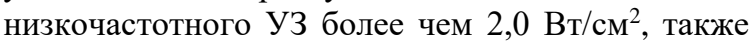

уменьшается степень очистки поваренной соли. При использовании только одного высокочастотного УЗ степень очистки поваренной соли была незначительной. Почти такой же была степень очистки поваренной соли без воздействия УЗ с использованием механического встряхивания, 80 встряхиваний / мин (табл. 4).

Таблица 4. Влияние интенсивности низкочастотного ультразвука на степень очистки поваренной соли

\begin{tabular}{|c|c|c|c|}
\hline \multirow{2}{*}{$\begin{array}{c}\text { Интенсивность У3, } \\
\text { Вт/см }{ }^{2}\end{array}$} & Мышьяк & Медь & Кадмий \\
\cline { 2 - 4 } & 82 & 85 & 83 \\
\hline 0,9 & 90 & 95 & 90 \\
\hline 1,0 & 90 & 97 & 91 \\
\hline 1,5 & 92 & 96 & 87 \\
\hline 2,0 & 83 & 89 & 7 \\
\hline 2,1 & 5 & 7 & 8 \\
\hline$* *$ & 6 & 7 & стень очистки поваренной соли, \% \\
\hline$* *$ & & & 95 \\
\hline
\end{tabular}

Частота высокочастотного УЗ 3,0 МГц. Интенсивность высокочастотного УЗ 1,5 Bm/ $\mathrm{cM}^{2}$. Частота низкочастотного УЗ 22,0 кГи. Время действия УЗ - 30 с. Конщентраџия гидроксида магния 4 ммоль/л, концентрация карбоната кальция 1 ммоль/л. * Без действия высокочастотной составляющей УЗ (действует только низкочастотный ультразвук). ** Без действия низкочастотной составляющей ультразвука (действует только высокочастотный ультразвук). *** без воздействия ультразвука, использование механического стряхивала - 80 встряхиваний/мин.

В табл. 5 приведены влияние времени воздействия УЗ на степень очистки поваренной соли. Как следует из табл. 5 время воздействия УЗ должно быть 30-40 с. При времени воздействия УЗ менее 30 с. степень очистки поваренной соли уменьшается. Увеличение времени воздействия УЗ более 40 с. приводит к уменьшению степени очистки поваренной соли.

Таблица 5. Влияние времени воздействия ультразвука на степень очистки поваренной соли

\begin{tabular}{|c|c|c|c|}
\hline \multirow{2}{*}{$\begin{array}{c}\text { Время } \\
\text { воздействияУ3, с }\end{array}$} & Мышьяк & Медь & Кадмий \\
\cline { 2 - 4 } & 85 & 89 & 88 \\
\hline 25 & 90 & 97 & 92 \\
\hline 30,0 & 91 & 98 & 92 \\
\hline 35,0 & 92 & 98 & 87 \\
\hline 40,0 & 83 & 86 & степень очистки поваренной соли, \% \\
\hline 45,0 & &
\end{tabular}

Частота высокочастотного УЗ 3,0 МГи. Интенсивность высокочастотного У3 1,5 $\mathrm{Bm} / \mathrm{cm}^{2}$. Частота низкочастотного У3 22,0 кГи. Интенсивность низкочастотного УЗ $1,5 \mathrm{Bm} / \mathrm{cm}^{2}$. Концентрация гидроксида магния - 4 ммоль/л, концентрация карбоната кальция - 1 ммоль/л.

В табл. 6 приведены влияние количества коллектора гидроксида магния и карбоната кальция на степень очистки поваренной соли. Как следует из табл. 6 количество гидроксида магния должна быть не менее 4 ммоль/л, а гидроксида кальция 1 - 2 ммоль / л. 


\begin{tabular}{|c|c|c|c|c|c|c|}
\hline \multirow{4}{*}{ Impact Factor: } & ISRA (India) & $=3.117$ & SIS (USA) & $=0.912$ & ICV (Poland) & $=6.630$ \\
\hline & ISI (Dubai, UAE & $=0.829$ & РИНЦ (Russia & $=0.156$ & PIF (India) & $=1.940$ \\
\hline & GIF (Australia) & $=0.564$ & ESJI (KZ) & $=8.716$ & IBI (India) & $=4.260$ \\
\hline & JIF & $=1.500$ & SJIF (Morocco & $=5.667$ & OAJI (USA) & $=0.350$ \\
\hline
\end{tabular}

Таблица 6. Влияние количества коллектора на степень очистки поваренной соли

\begin{tabular}{|c|c|c|c|}
\hline \multirow{2}{*}{$\begin{array}{c}\text { Количество } \\
\text { коллектора, ммоль/л }\end{array}$} & \multicolumn{3}{|c|}{ Степень очистки поваренной соли, \% } \\
\hline & Мышьяк & Медь & Кадмий \\
\hline \multicolumn{4}{|c|}{ Гидроксид магния (Соосаждение только на гидроксиде магния) } \\
\hline 1,0 & 18 & 24 & 21 \\
\hline 2,0 & 25 & 32 & 30 \\
\hline 3,0 & 38 & 45 & 43 \\
\hline 4,0 & 45 & 57 & 54 \\
\hline 4,5 & 56 & 65 & 61 \\
\hline 5,0 & 56 & 65 & 61 \\
\hline 6,0 & 56 & 65 & 61 \\
\hline \multicolumn{4}{|c|}{ Гидроксид магния (При этом количество карбоната кальция - 0,5 ммоль/л) } \\
\hline 1,0 & 21 & 24 & 21 \\
\hline 2,0 & 35 & 32 & 30 \\
\hline 3,0 & 57 & 45 & 43 \\
\hline 4,0 & 75 & 57 & 54 \\
\hline 4,5 & 87 & 85 & 82 \\
\hline 5,0 & 87 & 85 & 82 \\
\hline 6,0 & 87 & 85 & 82 \\
\hline \multicolumn{4}{|c|}{ Гидроксид магния (При этом количество карбоната кальция - 1,0 ммоль/л) } \\
\hline 1,0 & 38 & 47 & 44 \\
\hline 2,0 & 65 & 75 & 78 \\
\hline 3,0 & 87 & 89 & 89 \\
\hline 4,0 & 90 & 97 & 91 \\
\hline 4,5 & 90 & 97 & 92 \\
\hline 5,0 & 90 & 97 & 92 \\
\hline 6,0 & 90 & 97 & 92 \\
\hline \multicolumn{4}{|c|}{ Гидроксид магния (При этом количество карбоната кальция - 2,0 ммоль/л) } \\
\hline 1,0 & 42 & 55 & 54 \\
\hline 2,0 & 68 & 78 & 80 \\
\hline 3,0 & 89 & 89 & 89 \\
\hline 4,0 & 92 & 96 & 93 \\
\hline 4,5 & 92 & 96 & 93 \\
\hline 5,0 & 92 & 96 & 93 \\
\hline 6,0 & 92 & 96 & 93 \\
\hline \multicolumn{4}{|c|}{ Гидроксид магния (При этом количество карбоната кальция - 2,5 ммоль/л) } \\
\hline 1,0 & 19 & 21 & 25 \\
\hline 2,0 & 34 & 45 & 44 \\
\hline 3,0 & 68 & 63 & 69 \\
\hline 4,0 & 87 & 90 & 82 \\
\hline 4,5 & 87 & 90 & 81 \\
\hline 5,0 & 87 & 90 & 81 \\
\hline 6,0 & 87 & 90 & 81 \\
\hline \multicolumn{4}{|c|}{ Гидроксид кальция (Соосаждение только на гидроксиде кальция) } \\
\hline 1,0 & 3 & 8 & 7 \\
\hline 2,0 & 6 & 12 & 11 \\
\hline 3,0 & 12 & 25 & 29 \\
\hline 4,0 & 18 & 38 & 54 \\
\hline 4,5 & 18 & 43 & 54 \\
\hline 5,0 & 19 & 43 & 58 \\
\hline 6,0 & 19 & 43 & 58 \\
\hline
\end{tabular}

Частота высокочастотного УЗ 3,0 МГи. Интенсивность высокочастотного УЗ 1,5 Bm/ $\mathrm{cm}^{2}$. Частота низкочастотного УЗ 22,0 кГи. Интенсивность низкочастотного УЗ $1,5 \mathrm{Bm} / \mathrm{cm}^{2}$. Время воздействия УЗ $30 \mathrm{c}$.

В табл. 7 приведено сравнение способов очистки поваренной соли от примесей мышьяка, кадмия и меди: соосаждением на коллекторе гидроксиде магния -карбонате кальция с 


\begin{tabular}{|c|c|c|c|c|c|c|}
\hline \multirow{4}{*}{ Impact Factor: } & ISRA (India) & $=3.117$ & SIS (USA) & $=0.912$ & ICV (Poland) & $=6.630$ \\
\hline & ISI (Dubai, UAE & $=0.829$ & РИНЦ (Russia & $=0.156$ & PIF (India) & $=1.940$ \\
\hline & GIF (Australia) & $=0.564$ & ESJI (KZ) & $=8.716$ & IBI (India) & $=4.260$ \\
\hline & JIF & $=1.500$ & SJIF (Morocco & $=5.667$ & OAJI (USA) & $=0.350$ \\
\hline
\end{tabular}

интенсификацией

ультразвуком(предлагаемый

двухчастотным способ), соосаждением на коллекторе гидроксиде магния с интенсификацией ультразвуком низкой частоты [5]. Из табл. 7 следует, что в предлагаемом способе степень очистки концентрированных растворов поваренной соли ( $\geq 280$ г/л) выше, чем в способе согласно [5]. Так, предлагаемый способ обеспечивает достаточную степень очистки поваренной соли $\geq 90 \%$ для мышьяка до концентрации раствора поваренной соли - 280 г/л (степень очистки 90\%), для меди - до 300 г / л (степень очистки 90\%), для кадмия - до 280 г / л (степень очистки 91\%). А способ по [5] обеспечивает достаточную степень очистки поваренной соли $\geq 90 \%$ для мышьяка до концентрации раствора поваренной соли - 140 г/л (степень очистки 99\%), для меди до - 180 г/л (степень очистки 95\%), для кадмия до - 180 г / л (степень очистки 93\%).

Таблица 7. Сравнение способов очистки поваренной соли: соосаждением на коллекторе гидроксиде магния -карбонате кальция с интенсификацией двухчастотным ультразвуком, соосаждением на коллекторе гидроксиде магния с интенсификацией ультразвуком низкой частоты

\begin{tabular}{|c|c|c|c|c|c|}
\hline \multirow[b]{2}{*}{$\begin{array}{c}\text { Концентрация } \\
\text { поваренной } \\
\text { соли, г/л }\end{array}$} & \multirow[b]{2}{*}{$\begin{array}{c}\text { Сдержание } \\
\text { примесей до } \\
\text { очистки до } \\
\text { очистки, мкг }\end{array}$} & \multicolumn{2}{|c|}{ Предлагаемый способ } & \multicolumn{2}{|c|}{ Способ [5] } \\
\hline & & $\begin{array}{c}\text { Содержание } \\
\text { примесей } \\
\text { после } \\
\text { очистки, мкг }\end{array}$ & $\begin{array}{c}\text { Степень } \\
\text { очистки, } \\
\%\end{array}$ & $\begin{array}{c}\text { Содержание } \\
\text { примесей } \\
\text { после } \\
\text { очистки, мкг }\end{array}$ & $\begin{array}{c}\text { Степень очистки, } \\
\%\end{array}$ \\
\hline \multicolumn{6}{|c|}{ Мышьяк } \\
\hline 140,00 & 4,48 & 0,044 & 99 & 0,045 & 99 \\
\hline 180,00 & 5,76 & 0,173 & 97 & 0,864 & 85 \\
\hline 200,00 & 6,40 & 0,320 & 95 & 1,344 & 79 \\
\hline 250,00 & 8,00 & 0,480 & 94 & 5,440 & 32 \\
\hline 280,00 & 8,96 & 0,900 & 90 & 7,884 & 12 \\
\hline 300,00 & 9,60 & 1,632 & 83 & 8,832 & 8 \\
\hline 320,00 & 10,24 & 3,584 & 65 & 9,830 & 4 \\
\hline \multicolumn{6}{|c|}{ Медь } \\
\hline 140,00 & 54,6 & 0,546 & 99 & 0,547 & 99 \\
\hline 180,00 & 70,2 & 0,702 & 99 & 3,510 & 95 \\
\hline 200,00 & 78,0 & 0,780 & 99 & 8,580 & 89 \\
\hline 250,00 & 97,5 & 1,950 & 98 & 44,850 & 54 \\
\hline 280,00 & 109,2 & 3,276 & 97 & 73,230 & 33 \\
\hline 300,00 & 117,0 & 11,700 & 90 & 93,600 & 21 \\
\hline 320,00 & 124,8 & 29,952 & 76 & 109,824 & 12 \\
\hline \multicolumn{6}{|c|}{ Кадмий } \\
\hline 140,00 & 3,36 & 0,034 & 99 & 0,067 & 98 \\
\hline 180,00 & 4,32 & 0,043 & 99 & 0,302 & 93 \\
\hline 200,00 & 4,80 & 0,048 & 99 & 0,864 & 82 \\
\hline 250,00 & 6,00 & 0,180 & 97 & 3,120 & 52 \\
\hline 280,00 & 6,72 & 0,605 & 91 & 4,771 & 29 \\
\hline 300,00 & 7,20 & 1,080 & 85 & 5,832 & 19 \\
\hline 320,00 & 7,68 & 2,534 & 67 & 6,912 & 10 \\
\hline
\end{tabular}

Приведены усредненные результаты шести опытов. Для очистки использовали поваренную соль, содержашую (мас. \%): мышьяка - 0,032 мкг/2 (ПДК-1,0 мкг/2); кадмия - 0,024 мкг/2 (ПДК-0,1 мкг/2); меди - 0,39 мкг/2 (ПДК- 3,0 мкг/2);

\section{Conclusion}

Таким образом, экспериментально установлено, что при очистке концентрированных растворов поваренной соли $\geq 280$ г/л, использование в качестве коллектора смеси гидроксида магния и карбоната кальция, при количестве гидроксида магния не менее 4 ммоль/л, а гидроксида кальция 1 - 2 ммоль/л с интенсификацией воздействием ультразвука частотой 18 - 53 кГц, интенсивностью 1,0 - 2,5 $\mathrm{Bт} / \mathrm{cm}^{2}$ и ультразвука частотой 2-4 МГц интенсивностью $0,75-1,25 \mathrm{BT} / \mathrm{cm}^{2}$ в течение $30-45$ с позволяет повысить степень очистки концентрированных растворов поваренной соли с $12-33 \%$ до $90-97 \%$. 


\begin{tabular}{|c|c|c|c|c|c|c|}
\hline \multirow{4}{*}{ Impact Factor: } & ISRA (India) & $=3.117$ & SIS (USA) & $=0.912$ & ICV (Poland) & $=6.630$ \\
\hline & ISI (Dubai, UAE & $=0.829$ & РИНЦ (Russia & $=\mathbf{0 . 1 5 6}$ & PIF (India) & $=1.940$ \\
\hline & GIF (Australia) & $=0.564$ & ESJI (KZ) & $=8.716$ & IBI (India) & $=4.260$ \\
\hline & JIF & $=1.500$ & SJIF (Morocco & $=5.667$ & OAJI (USA) & $=0.350$ \\
\hline
\end{tabular}

\section{References:}

1. Goloperov, I. V., Belova, E. A., Baklanov, A. N., \& Baklanova, L. V. (2017). Solving the problems of safety in the production of iodied salt. ISJ Theoretical \& Applied Science, 04 (48): 70-75.

2. Baklanov, A. N., Baklanova, L. V., \& Golik, V. B. (1988). Problemy ochistki povarennoy soli ot primesey toksichnykh i bioaktivnykh elementov. Trudy VNIIsol', 35, № 6: 112-118.

3. Furman, A. A., Bel'dy, M. P., \& Sokolov, I. D. (1989). Povarennaya sol'. Proizvodstvo i primeneniye $\mathrm{v}$ khimicheskoy promyshlennosti. (p.272). Moscow: Khimiya.

4. Baklanov, A. N., \& Avdeyenko, A. P. (2009). Sposob ochistki khlorida natriya. Patent Ukrainy na poleznuyu model' № 45693. - Opubl. 15.11.2009. Byul. № 22 .

5. Chmilenko, F. A., Chuyko, V. T., Baklanov, A. N., \& Baklanova, L. V. (1990). Sposob ochistki rastvorov povarennoy soli ot primesey tyazholykh metallov. A. s. SSSR №1611863, SSSR. Opubl. 07.12.90. Byul. №45.

6. Margulis, M. A. (1986). Zvukokhimicheskiye reaktsii $i$ sonolyuminestsentsiya. (p.288). Moscow: Khimiya.
7. Yurchenko, O. I., Baklanov, A. N., Belova, E. A., Kalinenko, O. S., \& Baklanova, L. V. (2015). Ultrasound to intensify of food dry mineralization by the oxidants in vapor form. ISJ Theoretical \& Applied Science 07 (27): 122-129.

8. Yurchenko, O. I., Kalinenko, O. S., Baklanov, A. N., Belova, E. A., \& Baklanova, L. V. (2016). Ultrasound in the determination of lead, copper and cadmium in the sugar and products on its basis. ISJ Theoretical \& Applied Science, 01 (33): 158-163.

9. Baklanova, L. V., Belova, E. A., \& Baklanov, A. N. (2018). Improving the safety of the salt. Content determination various forms of chrom. ISJ Theoretical \& Applied Science, 04 (60): 4349.

10. Baklanov, A. N., Avdeenko, A. P., Chmilenko, F. A., \& Baklanova, L. V. (2011). Analiticheskaya khimiya povarennoy soli $i$ rassolov. (p.284). Kramatorsk: DGMA.

11. (2010). GOST 26930-86. Syr'ye i produkty pishchevyye. Metod opredeleniya mysh'yaka. (p.6). Moscow: Standartinform. 
ISRA $($ India $) \quad=\mathbf{3 . 1 1 7}$ SIS $($ USA $) \quad=\mathbf{0 . 9 1 2}$ ICV $($ Poland $) \quad=\mathbf{6 . 6 3 0}$

Impact Factor:

ISI $($ Dubai, UAE $)=\mathbf{0 . 8 2 9}$ РИНЦ $($ Russia $)=\mathbf{0 . 1 5 6}$

GIF $($ Australia) $=0.564$ ESJI $(\mathrm{KZ}) \quad=8.716$

$\mathrm{PIF}$ (India) $\quad=1.940$

JIF

$=\mathbf{1 . 5 0 0}$ SJIF $($ Morocco $)=\mathbf{5 . 6 6 7}$

IBI (India)

$=4.260$

OAJI (USA)

$=0.350$ 